\title{
Competitive Displacement of Serum Protein Binding of Radiopharmaceuticals with Amino Acid Infusion Investigated with $N$-Isopropyl-p ${ }^{-123}$ I-Iodoamphetamine
}

\author{
Noriyuki Kuga ${ }^{1,2}$, Naoto Shikano ${ }^{3}$, Norito Takamura ${ }^{4}$, Ryuichi Nishii ${ }^{5}$, Keishi Yamasaki ${ }^{6}$, Masato Kobayashi ${ }^{7}$, \\ Shigeki Nagamachi ${ }^{1}$, Shozo Tamura ${ }^{1}$, and Keiichi Kawai ${ }^{2,7}$ \\ ${ }^{I}$ Radiological Division, University of Miyazaki Hospital, University of Miyazaki, Miyazaki, Japan; ${ }^{2}$ Division of Health Science, \\ Graduate School of Health Sciences, Kanazawa University, Ishikawa, Japan; ${ }^{3}$ Department of Radiological Sciences, Ibaraki \\ Prefectural University of Health Sciences, Ibaraki, Japan; ${ }^{4}$ School of Pharmaceutical Sciences, Kyusyu University of Health and \\ Welfare, Miyazaki, Japan; ${ }^{5}$ Research Institute, Shiga Medical Center, Shiga, Japan; ${ }^{6}$ Faculty of Pharmaceutical Sciences, Sojo \\ University, Kumamoto, Japan; and ${ }^{7}$ Biomedical Imaging Research Center, University of Fukui, Fukui, Japan
}

\begin{abstract}
When a therapeutic drug is competitively displaced at the binding sites of serum proteins, the free fraction of the drug will be increased, with an increase in the manifestation of pharmacologic properties. In the case of molecular imaging probes, total clearance and tissue distribution are increased in such circumstances. The aim of this study was to observe the increase in cerebral accumulation of $N$-isopropyl- $p$-123|-iodoamphetamine ( ${ }^{123}$ I-IMP) using the protein-binding displacement method with amino acid infusion. Methods: ${ }^{123}$ |-IMP binding to human serum was investigated and identified. In addition, protein-binding sites and the specific binding sites of human serum albumin (HSA) and $\alpha_{1}$-acid glycoprotein (AGP) were examined by ultrafiltration. Then, serum-binding sites and the displacement effects of amino acid infusion, including Proteamin 12X Injection and Kidomin, were confirmed in vitro. Subsequently, displacement of ${ }^{123}$ IMP serum protein binding with Proteamin amino acid infusion was tested in monkeys. A scintigraphic study of ${ }^{123}$ I-IMP in monkeys loaded with or without Proteamin was performed, and timeactivity-curves of ${ }^{123}$-IMP brain accumulation in monkeys were evaluated. Results: ${ }^{123}$ I-IMP was bound to HSA site II and AGP to nearly equal extents. Compared with control conditions, loading with Proteamin and Kidomin markedly increased free fractions of binding site markers for HSA site II ( ${ }^{14} \mathrm{C}$-diazepam: $0.95 \% \pm 0.04 \%$ for control, $1.40 \% \pm 0.06 \%$ for Proteamin, $1.62 \% \pm 0.05 \%$ for Kidomin) and AGP ( ${ }^{3} \mathrm{H}$-propranolol: $10.60 \% \pm 0.32 \%$ for control, $13.18 \% \pm 0.14 \%$ for Proteamin, $13.82 \% \pm 0.72 \%$ for Kidomin). Amino acid infusions were thus suitable for use as displacers for binding site II and AGP. With use of Proteamin amino acid infusion to displace protein binding, the free fraction of ${ }^{125} \mathrm{I}-\mathrm{IMP}(14.95 \% \pm 0.74 \%)$ was significantly increased in serum (19.24\% $\pm 0.87 \%)$. In a ${ }^{123}$-IMP scintigraphic study of monkeys, average cerebral uptake in 2 monkeys increased by 1.34-fold with Proteamin. Our findings suggested that Proteamin treatment increased the free fraction of ${ }^{123 \mid-}$
\end{abstract}

Received Nov. 11, 2008; revision accepted Mar. 16, 2009.

For correspondence or reprints contact: Naoto Shikano, Department of Radiological Sciences, Ibaraki Prefectural University of Health Sciences,

4669-2 Ami, Ami-machi, Inashiki-gun, Ibaraki 300-0394, Japan.

E-mail: sikano@ipu.ac.jp

COPYRIGHT @ 2009 by the Society of Nuclear Medicine, Inc.
IMP, yielding rapid and pronounced cerebral accumulation in vivo. Conclusion: Amino acid infusion can improve brain accumulation by competitive displacement of serum protein binding in vivo. Further similar studies are needed with other radiopharmaceuticals.

Key Words: ${ }^{123}$ I-IMP; cerebral accumulation; amino acid infusion; serum protein binding; displacement

J Nucl Med 2009; 50:1378-1383

DOI: 10.2967/jnumed.108.060095

$I_{t}$ is generally accepted that only free drugs in serum exhibit pharmacologic activity. Coadministration of drugs with high protein-binding affinity may induce competitive displacement at specific binding sites and thus result in increased free drug concentration (1-3), with greater biologic activity of each drug than if either were administered alone. However, the increase in free drug concentration is often only transient, as a result of drug distribution and enhanced clearance.

Proteins bind a wide variety of drugs and thus significantly affect the pharmacokinetics and pharmacologic efficacy of such drugs. Contributions to drug binding in plasma include those of albumin, $\alpha_{1}$-acid glycoprotein (AGP), lipoproteins, and immunoglobulins (IgG). Several drugs bind with high affinity to one of the human serum albumin (HSA) sites and AGP $(4,5)$. Sudlow et al. characterized 2 sites for drug binding, site I (also referred to as the warfarin-binding site) and site II (the benzodiazepinebinding site) of HSA (6). Although interaction of many drugs with AGP has been reported, the binding site of AGP has not been determined. It has recently been shown that AGP contains a wide drug-binding region for basic, acidic, and neutral drugs and that the binding sites on AGP are not 
completely separate and in fact partially overlap and influence one another $(5,7)$.

Approximately $70 \%$ of $N$-isopropyl-p- ${ }^{123} \mathrm{I}$-iodoamphetamine (123I-IMP, Fig. 1), a diagnostic agent for determination of regional cerebral blood flow in SPECT, is bound to serum proteins $(8,9)$. If inhibitors with high protein-binding affinity could displace ${ }^{123}$ I-IMP serum protein binding, cerebral accumulation of this tracer would be increased. In fact, Kawai et al. reported an increase in ${ }^{123}$ I-IMP cerebral accumulation in monkeys using the protein-binding displacement method with 6MNA (a major metabolite of nabumetone) (10). We noted that an amino acid infusion could be administered more easily and safely than drugs. Amino acid infusions are widely used for parenteral nutrition and consist of water, glucose, salts, amino acids, vitamins, and sometimes emulsified fats. They are required for medical management of a variety of patients in a hypermetabolic state, as well as those who have neurologic disease, gastrointestinal disease, cancer, or psychiatric illness (11).

The purpose of this study was to investigate the displacement effects of ${ }^{123}$ I-IMP binding to 2 major human serum proteins, HSA and AGP. To identify the major binding proteins, we also evaluated the binding sites and effects of amino acid infusions on ${ }^{123}$ I-IMP serum protein binding to both HSA and AGP. In addition, we investigated whether cerebral accumulation of ${ }^{123}$ I-IMP was increased by amino acid infusion, using the competitive displacement method.

\section{MATERIALS AND METHODS}

\section{Materials}

Reagent-grade chemicals were used in this study. HSA (essentially fatty acid-free albumin), AGP, and human IgG were acquired from Sigma Chemical Co. Potassium warfarin, verapamil hydrochloride (Eisai), diazepam (Takeda Pharmaceutical Co., Ltd.), and propranolol hydrochloride (Dainippon Sumitomo Pharma Co., Ltd.) were also obtained. Amino acid infusions included Kidomin from Otsuka Pharmaceutical Factory, Inc., and Proteamin 12X Injection from Tanabe Seiyaku Co., Ltd. (Table 1). ${ }^{14} \mathrm{C}$-warfarin (2.1 MBq/ mmol) was synthesized and purified by Amersham Biosciences, and ${ }^{14} \mathrm{C}$-diazepam $(2.0 \mathrm{MBq} / \mathrm{mmol})$ and ${ }^{3} \mathrm{H}$-propranolol $(902.8 \mathrm{GBq} /$ mmol) were synthesized and purified by Perkin-Elmer Life Sciences ${ }^{123} \mathrm{I}$-IMP $(82.8 \mathrm{GBq} / \mathrm{mmol})$ and ${ }^{125} \mathrm{I}$-IMP $(10.5 \mathrm{GBq} / \mathrm{mmol})$ (Nihon Medi-Physics) were used as molecular imaging probes. The radiochemical purities of the IMP and radiolabeled compounds were greater than $95.0 \%$. Human pooled serum was prepared from blood samples obtained from 7 healthy male and female subjects. All subjects discontinued any medication for at least $5 \mathrm{~d}$ before blood sampling. The concentrations of albumin and AGP were determined to be 767 and $13 \mu \mathrm{M}$, respectively, using a COBAS Integra 400 Plus (Roche Diagnostics).

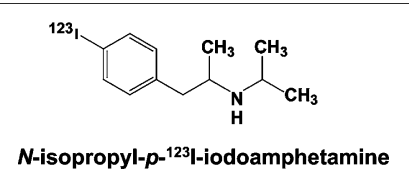

FIGURE 1. Chemical structure of ${ }^{123}$-IMP.
TABLE 1. Content of Amino Acid Infusions

\begin{tabular}{|lcc|} 
& \multicolumn{2}{c}{ Amino acid infusion } \\
\cline { 2 - 3 } Content & Proteamin & Kidomin \\
\hline L-arginine & 35.1 & 12.9 \\
\hline L-histidine & 17.1 & 11.3 \\
\hline L-isoleucine & 22.8 & 34.3 \\
\hline L-leucine & 43.4 & 53.4 \\
\hline L-lysine & 26.9 & 17.3 \\
\hline L-methionine & 14.5 & 10.1 \\
\hline L-phenylalanine & 29.5 & 15.1 \\
\hline L-threonine & 21.2 & 14.7 \\
\hline L-tryptophan & 4.6 & 6.1 \\
\hline L-valine & 29.4 & 42.7 \\
\hline Glycine & 104.4 & - \\
\hline L-proline & 46.2 & 13.0 \\
\hline L-serine & 22.2 & 14.3 \\
\hline L-aspartic acid & 7.6 & 3.8 \\
\hline L-glutamic acid & 3.5 & 3.4 \\
\hline L-tyrosine & 1.6 & 0.1 \\
\hline L-cystine & 0.5 & - \\
\hline L-cysteine & - & 4.1 \\
\hline L-alanine & 46.1 & 270.6 \\
\hline Total free amino acids & 476.6 & \\
\hline & & \\
\hline Data are mmol/L. Infusions & also contain electrolytes and \\
\hline carbohydrates. & & \\
\hline
\end{tabular}

\section{Identification of Protein Binding of ${ }^{123}$-IMP}

Serum protein binding of ${ }^{123} \mathrm{I}-\mathrm{IMP}(111 \mathrm{MBq} / \mathrm{mL})$ was measured by ultrafiltration (Ultracent-10; Tosoh). Centrifugal filter devices consisted of 2 compartments separated by a cellulose membrane, which had a molecular weight cutoff of 10,000 Da. ${ }^{123} \mathrm{I}$-IMP binding to human serum protein and to purified serum proteins such as HSA, AGP, and immunoglobulin (IgG) was examined. Mixtures $(900 \mu \mathrm{L})$ of ${ }^{123} \mathrm{I}-\mathrm{IMP}$ at $220 \mathrm{kBq}$ in $20 \mu \mathrm{L}$ of saline and serum (or HSA, AGP, or IgG solution) were centrifuged at 3,000 rpm for $10 \mathrm{~min}$ at room temperature (model 5900; Kubota). The radioactivities (counts $/ 20 \mu \mathrm{L}$ ) of the initial sample [I] and filtrate $[\mathrm{F}]$ were measured by a well-type scintillation counter (ARC-360; Aloka), and the free fraction and proteinbinding rate were then determined using the following equations:

$$
\begin{array}{cc}
\text { Free fraction }(\%)=[\mathrm{F}] /[\mathrm{I}] \times 100 & \text { Eq. } 1 \\
\text { Protein-binding rate }(\%)=100-\text { free fraction } & \text { Eq. } 2
\end{array}
$$

Human pooled sera were adjusted to an albumin concentration of $500 \mu \mathrm{M}$ with phosphate buffer ( $\mathrm{pH}$ 7.4). For use with purified human serum protein, solutions of HSA $(740 \mu \mathrm{M}, 4.9 \mathrm{~g} / 100 \mathrm{~mL}$ of phosphate buffer), AGP (17 $\mu \mathrm{M}, 75.0 \mathrm{mg} / 100 \mathrm{~mL}$ of phosphate buffer), and IgG (62 $\mu \mathrm{M}, 1.0 \mathrm{~g} / 100 \mathrm{~mL}$ of phosphate buffer) were prepared at a normal human serum concentration.

\section{Examination of Specific Sites of Protein Binding by ${ }^{123}$ I-IMP on HSA and AGP}

Effects of specific sites of protein binding by ${ }^{123}$ I-IMP on HSA and AGP were also examined in human pooled serum (albumin concentration, $500 \mu \mathrm{M}$ ) by ultrafiltration. Warfarin as a marker of HSA binding site I, diazepam as a marker of HSA binding site II, 
and propranolol and verapamil as markers of AGP were added to each serum sample at respective therapeutic concentrations (200 $\mu \mathrm{M})$ before addition of the radioactive sample. The molar ratio of HSA to each drug was 46.9. Free fraction rates were obtained using Equation 1. The control experiment used saline as a substitute for site marker. Adsorption of drugs onto the membrane and apparatus was negligible $(1,2,12)$.

\section{Examinations of Specific Sites of Protein Binding by Amino Acid Infusions in Serum}

The effects of amino acid infusion as a displacer were also examined in human serum (albumin concentration, $700 \mu \mathrm{M}$ ) by ultrafiltration. Proteamin and Kidomin were used because of their composition and content of amino acids. For confirmation of serum protein-binding sites of amino acid infusions, binding site markers such as ${ }^{14} \mathrm{C}$-warfarin $(1.23 \mathrm{MBq} / \mathrm{mL})$ and ${ }^{14} \mathrm{C}$-diazepam (3.7 MBq/mL) for binding sites I and II, respectively, and ${ }^{3} \mathrm{H}-$ propranolol $(37 \mathrm{MBq} / \mathrm{mL})$ for AGP were used. Mixtures $(200 \mu \mathrm{L})$ of binding site marker ( $5 \mu \mathrm{L}$ at $7.4 \mathrm{kBq} / \mathrm{mL}$ ), amino acid infusion $(2 \mu \mathrm{L})$, and serum were centrifuged at $3,000 \mathrm{rpm}$ for $10 \mathrm{~min}$ at $25^{\circ} \mathrm{C}$ (model 8800; Kubota). The molar ratios of HSA/L-tryptophan in Proteamin and HSA/L-tryptophan in Kidomin were 15.2 and 11.4 , respectively. Radioactivities (counts $/ 10 \mu \mathrm{L}$ ) of the initial sample $[\mathrm{I}]$ and filtrate $[\mathrm{F}]$ were measured with a liquid scintillation counter (LSC-5100; Aloka) after the addition of liquid scintillator (Clear-sol II; Nacalai Tesque) to scintillation vials. Free fraction rates were then determined using Equation 1.

\section{Effects of Amino Acid Infusions on Binding of ${ }^{123}$ |-IMP}

The effects of amino acid infusions as displacers on serum protein binding of ${ }^{123} \mathrm{I}$-IMP were examined. In this in vitro study, ${ }^{125} \mathrm{I}$-IMP (37 MBq/mL) was used instead of ${ }^{123} \mathrm{I}$-IMP. The free fraction of ${ }^{125}$ I-IMP was determined by ultrafiltration as described above, and free fractions were then calculated using Equation 1, with relative free fraction rates calculated as follows: Relative free fraction rate (fold) $=$ free fraction of sample/free fraction of control. HSA concentration in human serum was adjusted to $700 \mu \mathrm{M}$ with phosphate buffer ( $\mathrm{pH}$ 7.4). The AGP concentration in human serum was also adjusted to $20 \mu \mathrm{M}$ by adding AGP-purified serum protein, and $2-\mu \mathrm{L}$ aliquots of amino acid infusion were added to $200 \mu \mathrm{L}$ of a solution of ${ }^{125}$ I-IMP (1 $\mathrm{kBq}$ in $10 \mu \mathrm{L}$ ) and human serum. Normal saline solution was used as a control.

Displacement of ${ }^{123}$ I-IMP serum protein binding was attempted in monkeys with amino acid infusion. A scintigraphic study of ${ }^{123}$ I-IMP in 2 monkeys with or without loaded Proteamin was performed. Fasting Japanese monkeys $(4.0 \mathrm{~kg})$ were anesthetized with pentobarbital $(12.5 \mathrm{mg} / \mathrm{kg}$ of body weight, intraperitoneally) after Ketalar $(5.0 \mathrm{mg} / \mathrm{kg}$ of body weight, intramuscularly) and then received ${ }^{123}$ I-IMP (37 MBq in a 1.0$\mathrm{mL}$ bolus via the left cephalic vein, intravenously). To avoid circulatory disorder, saline was infused via the right cephalic vein. Supplemental heat to maintain body temperature was provided by a warm blanket. The depth of anesthesia was monitored by observing the pupils and using pulse oximetry. The animals recovered from anesthesia $5 \mathrm{~h}$ after the imaging study and were then maintained in the normal fashion in our facility. Dynamic whole-body planar data were acquired every $1 \mathrm{~min}$ for $60 \mathrm{~min}$ with a 2-head scintillation camera (Prism 2000; Picker International). Subsequently, brain SPECT was performed over $30 \mathrm{~min}$ (30 s/frame) using a 3-head scintillation camera (Prism 3000;
FIGURE 2. Protein binding of ${ }^{123}$ I-IMP to serum, HSA, AGP, and IgG at concentrations of 740,17 , and $62 \mu \mathrm{M}$, respectively. Each column represents mean \pm SD of 3 independent experiments.

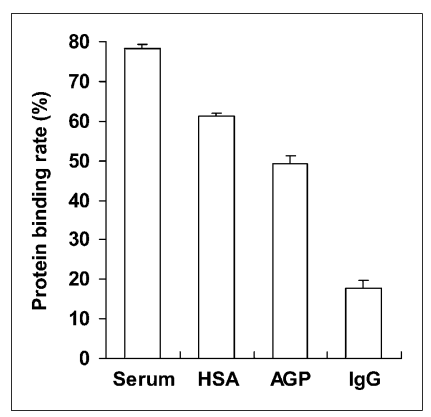

Picker International). For the displacement study, $5.0 \mathrm{~mL}$ of Proteamin (142.0 mg/kg of body weight, intravenously) was loaded just before the ${ }^{123} \mathrm{I}$-IMP injection. After ${ }^{123} \mathrm{I}$-IMP injection, Proteamin was also administered at $0.5 \mathrm{~mL} / \mathrm{min}$ for $30 \mathrm{~min}(14.2$ $\mathrm{mg} / \mathrm{kg}$ of body weight/min, intravenously). All animal experiments were approved by the Ethics Committee of the University of Miyazaki.

\section{Statistical Analysis}

Data are expressed as mean $\pm \mathrm{SD}$. Groups were compared using the Student $t$ test.

\section{RESULTS}

Determination of Protein Binding of ${ }^{123}$ |-IMP

Binding by ${ }^{123}$ I-IMP of human serum protein and purified serum protein was examined using ultrafiltration. In the in vitro binding assay shown in Figure 2, the percentage binding of ${ }^{123}$ I-IMP to human protein was $78.34 \% \pm$ $0.86 \%$. In addition, ${ }^{123}$ I-IMP bound moderately and almost equally to both HSA and AGP.

\section{Examinations of Specific Protein-Binding Sites for ${ }^{123}$-IMP on HSA and AGP}

Warfarin and diazepam are drugs that bind specifically to sites I and II, respectively, of $\operatorname{HSA}(7,13)$, whereas propranolol and verapamil bind specifically to AGP $(14,15)$. Free fractions of ${ }^{123}$ I-IMP were significantly increased, compared with control, by the HSA site II marker diazepam and the AGP site marker propranolol (increases of 1.11and 1.16-fold, respectively). There were no effects on

FIGURE 3. Effects of binding site markers on 123/-IMP protein binding. Normal saline solution was used as control. Concentration of HSA in human serum was adjusted to 500 $\mu \mathrm{M}$. Each site marker was loaded at $200 \mu \mathrm{M}$ final concentration. Each column represents mean $\pm S D$ of 3 independent experiments. ${ }^{\star} P<0.05$.

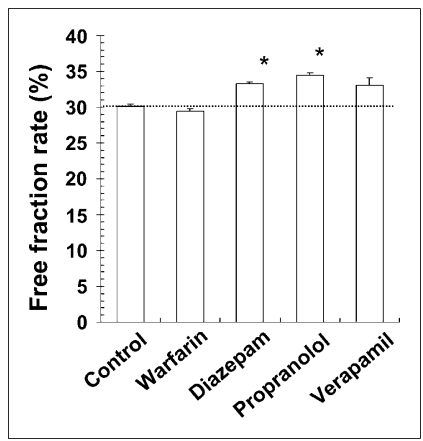




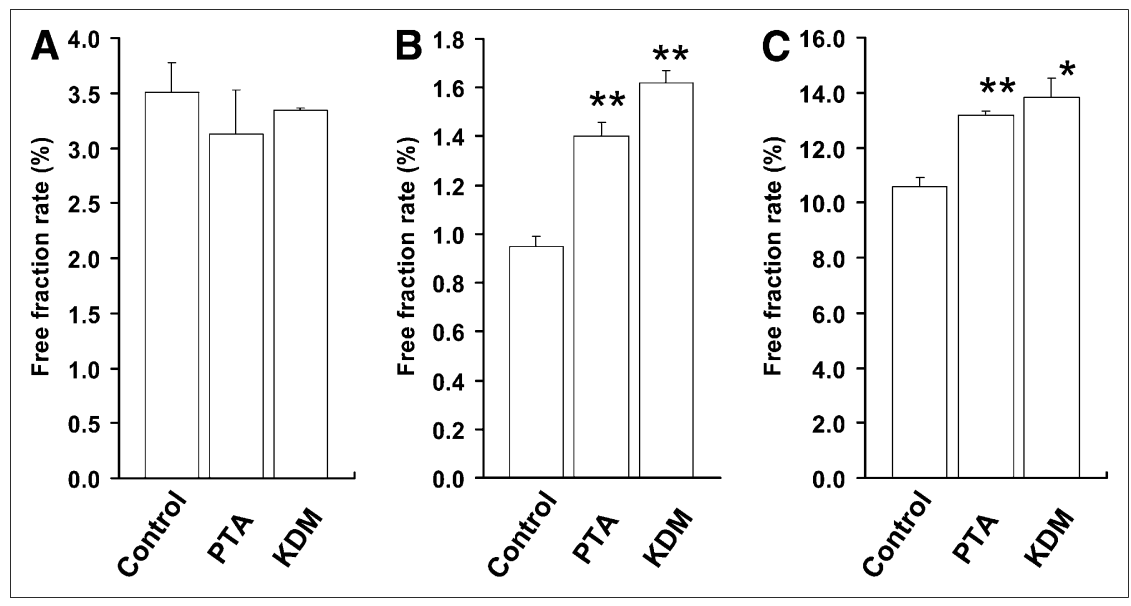

FIGURE 4. Free fraction rates of radiolabeled chemicals $\left({ }^{14} \mathrm{C}\right.$-warfarin $[\mathrm{A}]$, ${ }^{14} \mathrm{C}$-diazepam $[\mathrm{B}]$, and ${ }^{3} \mathrm{H}$-propranolol [C]) loaded with Proteamin (PTA) and Kidomin (KDM) in normal human serum. Concentration of HSA in human serum was adjusted to $700 \mu \mathrm{M}$, and $2.0-\mu \mathrm{L}$ aliquots of amino acid infusion were added to $200.0 \mu \mathrm{L}$ of radiolabeled chemical-human serum mixture. ${ }^{\star} P<$ 0.02 vs. control. ${ }^{* \star} P<0.003$ vs. control.

binding rate of the HSA site I marker warfarin (Fig. 3). ${ }^{123} \mathrm{I}$ IMP thus appeared to bind site II on HSA and AGP.

\section{Examinations of Specific Sites of Protein Binding by Amino Acid Infusions in Serum}

As shown in Figure 4, Proteamin and Kidomin markedly increased not only the free fraction of ${ }^{14} \mathrm{C}$-diazepam $(0.95 \% \pm$ $0.04 \%$ for control, $1.40 \% \pm 0.06 \%$ for Proteamin, and $1.62 \% \pm 0.05 \%$ for Kidomin) but also that of ${ }^{3} \mathrm{H}$-propranolol $(10.60 \% \pm 0.32 \%$ for control, $13.18 \% \pm 0.14 \%$ for Proteamin, and $13.82 \% \pm 0.72 \%$ for Kidomin). ${ }^{14} \mathrm{C}$-diazepam concentrations in human pooled serum were, with Proteamin and Kidomin, increased by 1.47- and 1.71-fold, respectively, over the control level. The free fraction of ${ }^{3} \mathrm{H}$-propranolol was also increased (by 1.24- to 1.30-fold) over the control level. The free fraction of ${ }^{14} \mathrm{C}$-warfarin was reduced. These findings indicated that the 2 amino acid infusions we tested are suitable displacers for binding site II on HSA and AGP.

\section{Effects of Amino Acid Infusion on Binding of ${ }^{123}$ |-IMP}

We evaluated the relative free fraction rates of ${ }^{125}$ I-IMP with amino acid infusions as displacers of serum protein binding in vitro. The free fractions of ${ }^{125}$ I-IMP in human pooled serum with Proteamin and Kidomin were significantly increased to 1.29 and 1.12 times the control level, respectively (Table 2). ${ }^{123}$ I-IMP scintigraphy was therefore performed on 2 monkeys with or without Proteamin.

TABLE 2. Free Fraction of ${ }^{125}$-IMP and Relative Free Fraction Rate with Proteamin and Kidomin

\begin{tabular}{lccc}
$\begin{array}{c}\text { Amino acid } \\
\text { infusion }\end{array}$ & $\begin{array}{c}\text { Free } \\
\text { fraction (\%) }\end{array}$ & $\begin{array}{c}\text { Relative free } \\
\text { fraction rate } \\
\text { (fold) }\end{array}$ & $\boldsymbol{P}^{*}$ \\
\hline $\begin{array}{l}\text { Control (saline) } \\
\text { Proteamin }\end{array}$ & $14.95 \pm 0.74$ & - & - \\
Kidomin & $19.24 \pm 0.87$ & $1.29 \pm 0.06$ & $<0.02$ \\
& $16.79 \pm 0.87$ & $1.12 \pm 0.06$ & $<0.02$ \\
\hline & & & \\
&
\end{tabular}

Dynamic whole-body images and time-activity curves of ${ }^{123}$ I-IMP for each organ in monkeys are shown in Figures 5A and 6, respectively. Rapid cerebral accumulation was observed with Proteamin loading in both monkeys. The average cerebral uptake of 2 monkeys increased by 1.34fold with Proteamin. Particularly, the plateaus of the timeactivity curves were slightly shifted within 15 min with Proteamin loading in monkey 2 . The plateaus of radioactivity in the brain of monkey 1 were significantly increased (1.44-fold), compared with the control condition, whereas relative changes in regional cerebral accumulation on brain SPECT (Fig. 5B) were not observed. These findings suggested that Proteamin treatment increased the free fraction of ${ }^{123}$ I-IMP and thus yielded rapid and pronounced cerebral accumulation in vivo.

\section{DISCUSSION}

Systemically administered drugs bind reversibly to serum proteins, and only free drugs in serum exhibit pharmacologic effects. The binding of drugs to proteins is an important factor inhibiting tissue distribution and excretion. The usefulness of protein-binding displacement has been reported. Takamura et al. suggested that coadministration of bucolome as a displacer of binding site I on HSA is effective in treating nephritic syndrome (16). ${ }^{123}$ I-IMP exhibits high protein binding. We therefore attempted to increase cerebral accumulation of ${ }^{123}$ I-IMP using the competitive displacement method with amino acid infusion, which is applied clinically for parenteral nutrition and easily administered to maintain high blood concentrations of parenteral formula.

In our in vitro binding assay, approximately $78 \%$ of ${ }^{123} \mathrm{I}-$ IMP was bound to human serum protein, which has a high affinity to HSA site II (one of the specific binding sites of HSA) and AGP (Figs. 2 and 3). Yamasaki et al. have suggested that L-tryptophan in amino acid fluids specifically inhibits binding site II of HSA (12). Furthermore, we found that displacement by amino acid infusions might 

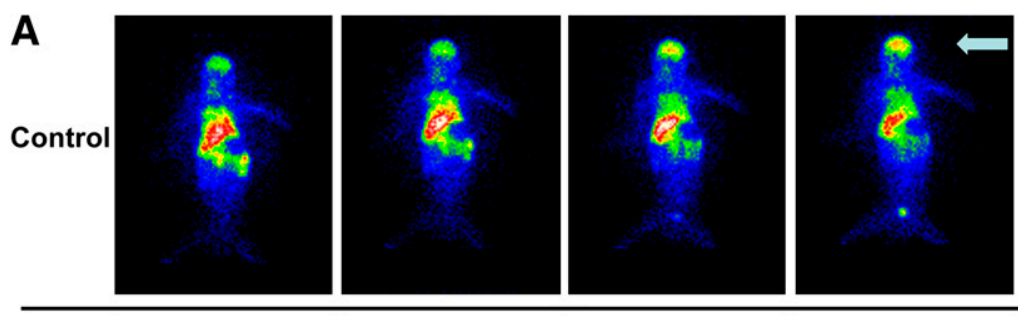

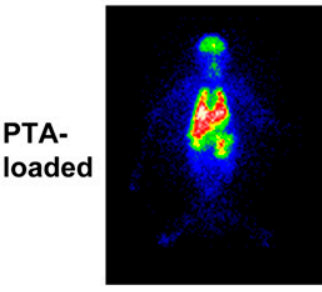

$5 \mathrm{~min}$

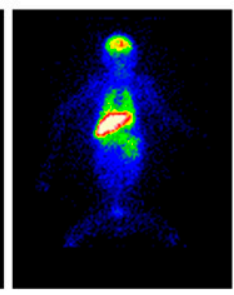

$10 \mathrm{~min}$

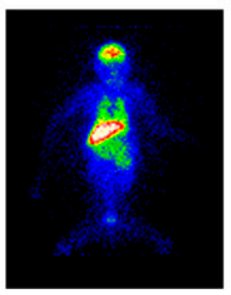

$30 \mathrm{~min}$

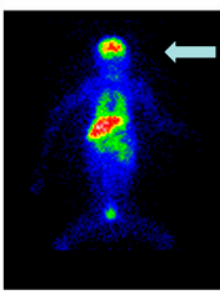

$60 \mathrm{~min}$

B

FIGURE 5. 123/-IMP whole-body scintigraphy (A) and brain SPECT (B) with or without Proteamin loading in same monkey (monkey 1). Proteamin (PTA; $5.0 \mathrm{~mL}$ ) was loaded just before ${ }^{123}$ I-IMP injection. After ${ }^{123}$-IMP injection, Proteamin was also administered at $0.5 \mathrm{~mL} / \mathrm{min}$ for 30 $\min$.

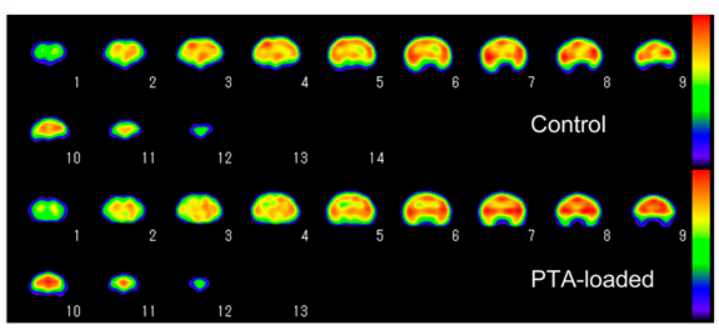

affect AGP and binding site II of HSA (Fig. 4). The amino acid infusions we tested are thus suitable for clinical use as displacers of binding site II of HSA and AGP.

These amino acid infusions were also found to have displacement effects on ${ }^{125}$ I-IMP in human pooled serum. The free fraction of ${ }^{125}$ I-IMP loaded with amino acid infusion, especially Proteamin, was significantly increased (1.29 times), compared with control (Table 2). Species differences were observed in displacement effects (10). A monkey study was then performed to confirm the displacement effects of Proteamin found in human serum studies, since a species similarity was expected between monkeys and humans. In the monkey scintigraphic study, rapid cerebral accumulation and a slight shift of time-activity curve plateaus were observed with Proteamin loading (Figs. 5 and 6). The radioactivity plateaus in brain were 1.24- and 1.44-fold higher in Proteamin-loading monkeys than those in control monkey 1 and control monkey 2, respectively. Kawai et al. reported that the combination of both binding inhibitors (of HSA site II and AGP) appears to exert a synergistic effect in displacement of IMP serum binding (10). It thus appeared that Proteamin treatment increased the free fraction of ${ }^{123}$ I-IMP and displaced ${ }^{123}$ I-IMP serum binding via a domino effect, yielding rapid and pronounced cerebral accumulation in vivo. The initial gradients of the brain accumulation curve with Proteamin loading were 1.3and 1.4-fold higher in Proteamin-loading monkeys than in control monkey 1 and control monkey 2 , respectively. We

FIGURE 6. Time-activity curves of 123/-IMP monkey 1 (A) and monkey 2 (B) on dynamic scintigraphy in same monkey. Findings with or without Proteamin (PTA) loading are shown for ${ }^{123}$ |IMP accumulation in monkey.
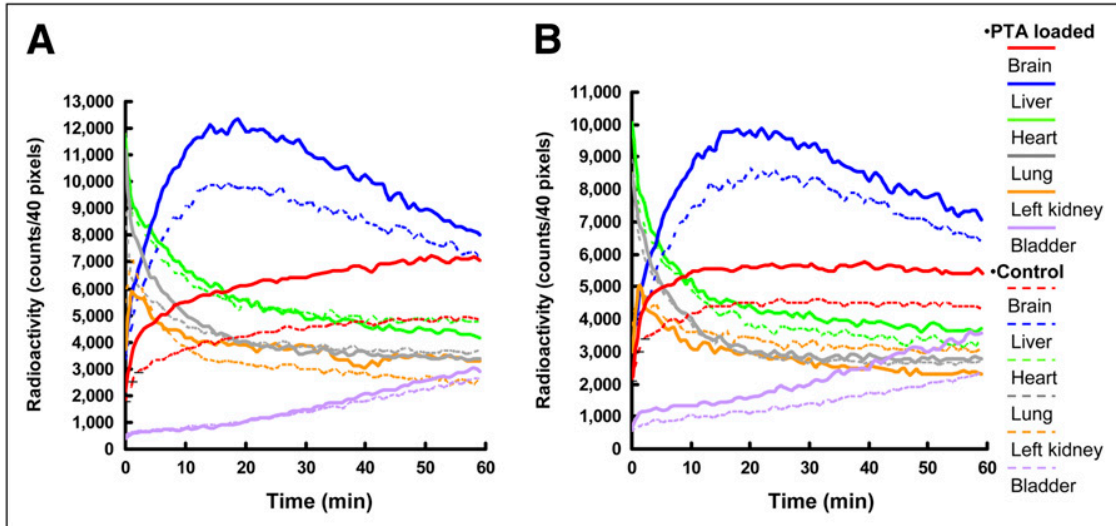
observed that the IMP uptake rate in the brain was increased just after administration. Furthermore, we observed different initial gradients in lung accumulation curves between Proteamin loading and control (Fig. 6). The free drug hypothesis assumes that only the free fraction of the drug in plasma can penetrate tissue and that drug transport in tissue is governed by the free drug concentration gradient between plasma and tissue, until equilibrium is reached $(17,18)$. Thus, it appeared that Proteamin treatment increased the free ${ }^{123}$ I-IMP concentration gradient, with a tendency toward shift and a short time to peak value. However, the mechanism of IMP uptake into brain capillaries requires further study. These findings suggested the possibility of controlling the pharmacokinetics of ${ }^{123}$ I-IMP and imaging in clinical applications. Such a possibility could improve not only cerebral accumulation but also the signal-to-noise ratio of scintigraphic images. On the other hand, the possibility exists that reduced administration of ${ }^{123}$ I-IMP can yield image quality equal to that currently obtainable, with control of diagnostic costs. The displacement method could easily be applied to human studies under the conditions of the present examination. Displacement of radiopharmaceutical binding to serum proteins, we believe, provides a higher target organ accumulation and shortened imaging times, as well as higher signal-to-noise ratios in imaging.

\section{CONCLUSION}

This study showed that application of amino acid infusions as displacers of serum protein binding significantly increased the free fraction of IMP in vitro in serum and improved cerebral accumulation in monkey brain on whole-body dynamic scintigraphy. Amino acid infusions could thus be clinically useful for competitive displacement and regulation of the tissue distribution and kinetics of molecular imaging probes with high protein binding. Further similar studies are needed with other radiopharmaceuticals.

\section{ACKNOWLEDGMENTS}

We thank Hideo Arita, Yasuyoshi Kuroiwa, Dr. Seigo Fujita, Dr. Takashi Jinnouchi, and the rest of the staff of the Department of Radiology, University of Miyazaki Hospital, as well as the members of the Kawai Laboratory of Kanazawa University, for technical assistance.

\section{REFERENCES}

1. Takamura N, Haruta A, Kodama H, et al. Mode of interaction of loop diuretics with human serum albumin and characterization of binding site. Pharm Res. 1996;13:1015-1019.

2. Takamura N, Maruyama T, Ahmed S, Suenaga A, Otagiri M. Interactions of aldosterone antagonist diuretics with human serum proteins. Pharm Res. 1997; 14:522-526.

3. Takamura N, Maruyama T, Otagiri M. Effects of uremic toxins and fatty acids on serum protein binding of furosemide: possible mechanism of the binding defect in uremia. Clin Chem. 1997;43:2274-2280.

4. Kragh-Hansen U, Chuang VTG, Otagiri M. Practical aspects of the ligandbinding and enzymatic properties of human serum albumin. Biol Pharm Bull. 2002;25:695-704.

5. Otagiri M. A molecular functional study on the interaction of drugs with plasma proteins. Drug Metab Pharmacokinet. 2005;20:309-323.

6. Sudlow G, Birkett DJ, Wadem DN. The characterization of two specific drug binding sites on human serum albumin. Mol Pharmacol. 1975;11:824-832.

7. Matsumoto K, Sukimoto K, Nishi K, Maruyama T, Suenaga A, Otagiri M. Characterization of ligand binding sites on the $\alpha_{1}$-acid glycoprotein in humans, bovines and dogs. Drug Metab Pharmacokinet. 2002;17:300-306.

8. Winchell HS, Baldwin RM, Lin TH. Development of I-123-labeled amines for brain studies: localization of I-123-iodophenylalkyl amines in rat brain. $\mathrm{J} \mathrm{Nucl}$ Med. 1980;21:940-946.

9. Winchell HS, Horst WD, Braun L, et al. $N$-isopropyl-[ $\left[{ }^{123} \mathrm{I}\right] p$-iodoamphetamine: single-pass brain uptake and washout; binding to brain synaptosomes; and localization in dog and monkey brain. J Nucl Med. 1980;21:947-952.

10. Kawai K, Nishii R, Shikano N, et al. Serum protein binding displacement: theoretical analysis using a hypothetical radiopharmaceutical and experimental analysis with ${ }^{123}$ I- $N$-isopropyl-p-iodoamphetamine. Nucl Med Biol. 2009;36:99-106.

11. Murphy A, Scott A. Artificial nutritional support: what are the options? Hosp Pharm. 2000;7:146-154.

12. Yamasaki K, Kuga N, Takamura N, et al. Inhibitory effects of amino-acid fluids on drug binding to site II of human serum albumin in vitro. Biol Pharm Bull. 2005;28:549-552.

13. Kragh-Hansen U. Relations between high-affinity binding sites for L-tryptophan, diazepam, salicylate and Phenol Red on human serum albumin. Biochem J. 1983;209:135-142.

14. Takamura N, Kawai K, Nishii R, et al. Potentialization mechanism of domino displacement on ${ }^{123}$ I-IMP serum protein binding. J Labelled Comp Radiopharm. 2001;44(suppl):465-467.

15. Svensson CK, Woodruff MN, Baxter JG, et al. Free drug concentration monitoring in clinical practice: rationale and current status. Clin Pharmacokinet. 1986;11:450-469.

16. Takamura N, Maruyama T, Chosa E, et al. Bucolome, a potent binding inhibitor for furosemide, alters the pharmacokinetics and diuretic effect of furosemide: potential for use of bucolome to restore diuretic response in nephrotic syndrome. Drug Metab Dispos. 2005;33:596-602.

17. Gillette JR. Overview of drug-protein binding. Ann N Y Acad Sci. 1973;226:6-17.

18. Riant P, Urien S, Albengres E, Renouard A, Tillement JP. Effects of the binding of imipramine to erythrocytes and plasma proteins on its transport through the rat blood-brain barrier. J Neurochem. 1988;51:421-425. 